\title{
Concepções acerca da Religiosidade: a Perspectiva da Criança
}

\section{Conceptions of Religiosity: A Child's Perspective}

\section{Las Concepciones de la Religiosidad: la Perspectiva de un Niño}

\author{
Ana Paula Sesti Becker* \\ Universidade Federal de Santa Catarina - UFSC, Florianópolis, Santa Catarina, \\ Brasil
}

\section{Josiane Delvan da Silva**}

Universidade do Vale do Itajaí - UNIVALI, Itajaí, Santa Catarina, Brasil

\begin{abstract}
RESUMO
A religiosidade, a busca pelo Sagrado e as indagações quanto à espiritualidade, têm sido o foco de investigações em diferentes áreas e contextos científicos. Este artigo tem como objetivo analisar as concepções acerca da religiosidade de crianças escolarizadas entre 6 a 10 anos de idade. $O$ estudo constituiu-se como exploratório-descritivo de abordagem qualitativa. Para a coleta de dados utilizou-se a entrevista semi-estruturada e o desenho temático envolvendo 10 crianças, sendo (5) crianças de um colégio de ensino regular laico e (5) crianças de um colégio de ensino regular religioso. Os dados foram analisados a partir da técnica de análise de conteúdo temático categorial. Os resultados evidenciaram dados similares quanto às representações que as crianças têm acerca da religiosidade, uma vez que a representação que a maioria dos participantes possui em relação ao Divino contempla uma noção concreta e personificada a partir do estágio cognitivo em que se encontram. Além disso, o envolvimento parental constituiu-se como um aspecto importante para o desenvolvimento da religiosidade infantil.
\end{abstract}

Palavras-chaves: criança, religiosidade, espiritualidade, cognição.

\begin{abstract}
Religiosity, the search for the Holy and inquiries regarding spirituality have been the focus of investigations in different areas and scientific contexts. This article aims to analyze the conceptions of religiosity that school children aged 6 to 10 years of age have. The study consisted as an exploratory and descriptive qualitative approach. To collect the data we used the semistructured interviews and thematic drawings with 10 children, (5) children of a school of education and secular (5) children of a college of education religious. Data were analyzed using content analysis. The results showed similar data regarding representations that children have about religiosity, since the representation that most of the participants nourish symbols related to the Divine, run through a concrete notion depending on the cognitive stage where they are. In addition, parental involvement was
\end{abstract}


established as an important aspect for the development of children's religiosity.

Keywords: child, religiosity, spirituality, cognition.

\section{RESUMEN}

La religiosidad y la búsqueda de las consultas relativas a la espiritualidad, han sido el foco de las investigaciones en las diferentes áreas y contextos científicos. Esta investigación analiza las concepciones de la religiosidad que los escolares de entre 6 y 10 años de edad tienen. El estudio consistió como enfoque cualitativo, exploratorio y descriptivo. Para recolectar los datos se utilizó la entrevista semi-estructurada y un diseño temático con 10 niños, y (5) los niños de un colegio de educación secular y (5) los niños de un colegio de educación religiosa. Los datos se analizaron mediante análisis de contenido. Los resultados mostraron datos similares con respecto a las representaciones que tienen los niños acerca de la religión, ya que la representación que la mayoría de los participantes nutre de símbolos en relación con lo divino, y se ejecuta a través de una noción concreta personificación de la etapa cognitiva donde están. Además, la participación de padres se estableció como un aspecto importante para el desarrollo de la religiosidad de los niños.

Palabras clave: infantil, la religiosidad, la espiritualidad, la escuela.

\section{Introdução}

A religiosidade, a busca pelo Sagrado e as indagações quanto à espiritualidade, têm sido o foco de investigações no contexto clínico e, especialmente entre pesquisadores da área da saúde. As pesquisas brasileiras direcionadas para a análise de tal temática ainda são, por ora, incipientes. No entanto, o interesse e a relevância pelo tema têm ganhado espaço em diferentes áreas e contextos científicos (Almeida, Pinsky, Zaleski \& Laranjeira, 2010; Cardoso \& Ferreira, 2009).

Pietrukowicz (2001) salienta que a religiosidade permite às pessoas interagirem com outras ou em grupo, a partir do estabelecimento de um contato sistemático, criando vínculos de amizade e pertencimento. $O$ apoio social recebido produz um efeito benéfico como expressão de saúde para os sujeitos que participam das atividades. Neste sentido, as pessoas modificam seus comportamentos habituais, tendo maior capacidade para enfrentamento de situações delicadas e dolorosas, com a autoestima preservada a partir da descoberta do potencial que possuem. Tal processo repercute em uma melhor qualidade de vida individual e relacional.

Embora pareçam sinônimos, religiosidade e espiritualidade são definidas de diferentes maneiras e os seus conceitos têm sido revistos e atualizados nas últimas décadas. De acordo com Gobatto e Araújo (2013), a religiosidade pode ser compreendida como um conjunto de práticas que um indivíduo acredita e segue uma religião. Portanto, parte-se de um sistema de adoração/doutrina específica 
partilhada com um grupo, no qual se relaciona a uma instituição religiosa e/ou igreja, proposta por um sistema de práticas religiosas compartilhadas. Já o termo espiritualidade norteia questões quanto ao propósito da vida e à razão de viver, não limitado a tipos de crenças ou práticas. Considera-se que a espiritualidade seja adjetivada, por exemplo, como uma espiritualidade teísta, cristã, budista, ateísta, etc. Todavia, é bastante comum a vivência simultânea destes fenômenos na vida pessoal daqueles que os praticam (Gobatto \& Araújo, 2013; Paiva, 2011).

Mas quando a religiosidade se constitui para o ser humano? Partindo deste questionamento, o interesse voltou-se para a investigação da religiosidade na infância. Fundamentando-se no contexto e no meio em que o sujeito está inserido, Mota (2005) entende que a criança construirá o seu significado da imagem de Deus e das práticas religiosas a partir das informações e experiências que receberá durante o seu desenvolvimento. Sobre isto, Neves (2005) aponta que as crianças constroem, ligadas a este mundo real, representações não só dos objetos, mas também das pessoas que lhes são significativas, concomitantemente em que constroem a própria representação de si. É neste processo de construção da identidade e dos fenômenos que a cercam, que a criança passa a conceber, idealizar e experienciar a religiosidade.

Crianças com idade entre 2 a 6 anos têm como principal característica cognitiva a incapacidade de sair das percepções imediatas e pensar conceitualmente. Neste estágio inicia-se a socialização da ação (troca entre indivíduos), uma interiorização da palavra e da ação. No tocante ao nível de desenvolvimento afetivo, seguem-se sentimentos interindividuais (simpatias, respeito e antipatias) que, segundo os conceitos piagetianos, estão ligados à socialização das ações, provenientes das relações entre adultos e crianças (Belsky, 2010; Piaget, 1999).

As que possuem idade entre 7 aos 11 anos, o tipo de cognição característico é marcado pela capacidade de raciocinar sobre o mundo de um modo mais lógico e adulto (Belsky, 2010). Ou seja, a criança tem a capacidade de considerar duas variáveis ao mesmo tempo, distinguir com facilidade fantasia de realidade, utilizando-se do raciocínio, não deixando que a percepção interfira no domínio das experiências e eventos concretos (Piaget, 1999).

Diante do exposto, o objetivo desta pesquisa foi analisar as concepções acerca da religiosidade que crianças escolarizadas possuem. Mais especificamente, pretendeu identificar a crença religiosa das crianças participantes do estudo; descrever a compreensão que estas possuem acerca da religiosidade; verificar a fonte das informações recebidas por estas crianças acerca da religiosidade; levantar quais as práticas religiosas que realizam 
habitualmente e apontar a finalidade da religiosidade no cotidiano para estas crianças.

\section{Método}

A pesquisa é do tipo qualitativa, de caráter descritivo-exploratória, tendo em vista a finalidade de compreender a natureza do fenômeno, suas características e variáveis (Minayo, 1998), uma vez que proporciona lidar com os aspectos mais subjetivos, amplos e com maior riqueza de detalhes (Campos, 2004; Neves, 1996).

\subsection{Contexto}

O estudo foi realizado em duas escolas particulares de ensino, localizadas em uma cidade do litoral catarinense. A fim de caracterizar estas instituições e distinguir a finalidade da amostragem, denominou-se "Escola A", cujo projeto político pedagógico ressalta os valores, princípios e doutrinas religiosas. Enquanto, a "Escola B" investigada, não define em seu projeto pedagógico os princípios religiosos como escopo para suas atividades e valores adotados.

\subsection{Participantes}

Participaram desta pesquisa 10 crianças, sendo: cinco (5) da "Escola $A^{\prime \prime}$ e cinco (5) da "Escola B". Compreendeu-se a faixa etária de 6 a 10 anos de idade entre os participantes matriculados no $1^{\circ}$ ano, $1^{\text {a }}$ série do $2^{\circ}$ ano e assim, sucessivamente até a $4^{a}$ série do $5^{\circ}$ ano do Ensino Fundamental das escolas participantes da pesquisa. A amostra contemplou duas crianças do sexo feminino e três do sexo masculino na "Escola $A$ " e três do sexo feminino e duas do sexo masculino na "Escola B". A fim de preservar o anonimato dos participantes, os nomes das crianças são fictícios, conforme a descrição nas Tabelas 01 e 02:

Tabela 01

Identificação das crianças da "Escola A" do Ensino Fundamental

\begin{tabular}{l|l|l}
\hline NOME DA CRIANÇA & IDADE & ESCOLARIDADE \\
\hline Carla & 06 & $1^{\circ}$ ano \\
\hline Ricardo & 07 & $1^{a}$ série do $2^{\circ}$ ano \\
\hline Tiago & 08 & $2^{a}$ série do $3^{\circ}$ ano \\
\hline Lucas & 09 & $3^{a}$ série do $4^{\circ}$ ano \\
\hline Beatriz & 10 & $4^{a}$ série do $5^{\circ}$ ano \\
\hline
\end{tabular}


Tabela 02

Identificação das crianças da "Escola B" do Ensino Fundamental

\begin{tabular}{l|l|l}
\hline NOME DA CRIANÇA & IDADE & ESCOLARIDADE \\
\hline Alice & 06 & $1^{\circ}$ ano \\
\hline Samuel & 07 & $1^{\text {a } \text { série do } 2^{\circ} \text { ano }}$ \\
\hline Isabel & 08 & $2^{a}$ série do $3^{\circ}$ ano \\
\hline Mateus & 09 & $3^{a}$ série do $4^{\circ}$ ano \\
\hline Gabriela & 10 & $4^{a}$ série do $5^{\circ}$ ano \\
\hline
\end{tabular}

\subsection{Instrumentos}

Utilizou-se como instrumentos para a coleta de dados a entrevista semi-estruturada e o desenho temático. Conforme Goldberg, Yunes e Freitas (2005) o desenho temático se constitui um importante meio de comunicação e representação da criança, apresentando-se como atividade fundamental do indivíduo em seu desenvolvimento. Isto, porque permite à criança organizar informações, processar experiências vividas e pensadas, transmitindo seu aprendizado e representando sua forma singular de conceber o mundo.

Os dados obtidos por meio das entrevistas foram analisados qualitativamente a partir da técnica de análise de conteúdo que consiste no tratamento e análise de informações constantes de um documento, sob forma de discursos pronunciados em diversas linguagens: escritos, orais, imagens, gestos (Franco, 2005). Os dados oriundos das entrevistas foram organizados em categorias temáticas, com base nos objetivos pelos quais se delineou o presente estudo, bem como dos conteúdos que emergiram das entrevistas, totalizando cinco categorias, a saber: a) Conceito de religiosidade; b) Fonte das informações recebidas sobre religiosidade; c) Práticas religiosas; d) Finalidade das práticas religiosas; e) compreensão das crianças sobre Deus.

Os critérios utilizados para a análise do desenho temático foram: as características formais do desenho como o tamanho, o traçado, a proporção, as cores utilizadas, detalhes, distribuição no espaço do papel e precisamente, o conteúdo expresso através do desenho seguido das narrativas relatadas frente à produção do mesmo. Estes são indicadores que objetivam analisar a relação que a criança estabelece com o fenômeno e como o concebe no contexto ao qual está inserida (Bellodi, Romão \& Jacquemin, 1997).

\subsection{Procedimentos}

Após a anuência das duas instituições de Ensino para a autorização da pesquisa e aprovação no Comitê de Ética sob o parecer n. 50750 de 22 de junho de 2012, contatou-se com os participantes da amostra, após uma escolha não intencional mediante a realização de 
sorteio para selecionar a criança das turmas a fim de compor o grupo representativo de cada uma das escolas. Posteriormente, foi entregue - Termo de Consentimento Livre e Esclarecido para os pais preencherem, solicitando-Ihes a assinatura e agendou-se um próximo encontro para a coleta de dados. As entrevistas foram realizadas individualmente em uma sala em cada uma das instituições específica para tal fim. Após a entrevista, solicitou-se ao participante que fizesse um desenho sobre 0 assunto que foi discutido com 0 pesquisador.

\section{Resultados e Discussão}

Concernente ao conceito de religião, a maioria das crianças pesquisadas não conseguiu definir o significado da terminologia "religião"; todavia, quando questionadas sobre o que concebiam por "igreja ou Deus", as respostas emergiram. Estas compreenderam a temática como um lugar específico para realizar orações, cânticos, aprender sobre o Cristianismo, desenvolver novos hábitos e ainda, conceberam como a reunião de um grupo de pessoas de diferentes crenças religiosas. Conforme se evidenciam nos relatos:

Igreja pra mim é onde a gente vai pra buscar a Deus, por tudo aquilo que Ele fez na cruz por nós (Beatriz, 10 anos).

Igreja é um lugar onde a gente vai pra tirar as más coisas que a gente fez e pra rezar pra alguma pessoa (Isabel, 8 anos).

As falas acima ilustram o conceito de religiosidade atribuído a um lugar e, neste caso, de uma igreja, onde as pessoas vão para uma determinada finalidade como desenvolver a religiosidade, além de parecer um local de reparação quanto às condutas morais do sujeito, passível de distanciar-se das práticas consideradas inadequadas. De acordo com Neves (2005), a maneira das crianças construírem suas idéias a respeito de temas abstratos, especialmente vinculados à religiosidade, relaciona-se diretamente à bagagem contextual que Ihes é oferecida, a educação que recebem, a religião na qual são introduzidas e aos tipos de tabus e aspectos culturais da sociedade da qual fazem parte. Verifica-se nos discursos prévios uma intencionalidade no ato de ir à igreja, bem como do simbolismo que isto remete para tais crianças. O desenho abaixo retrata a discussão anterior: 


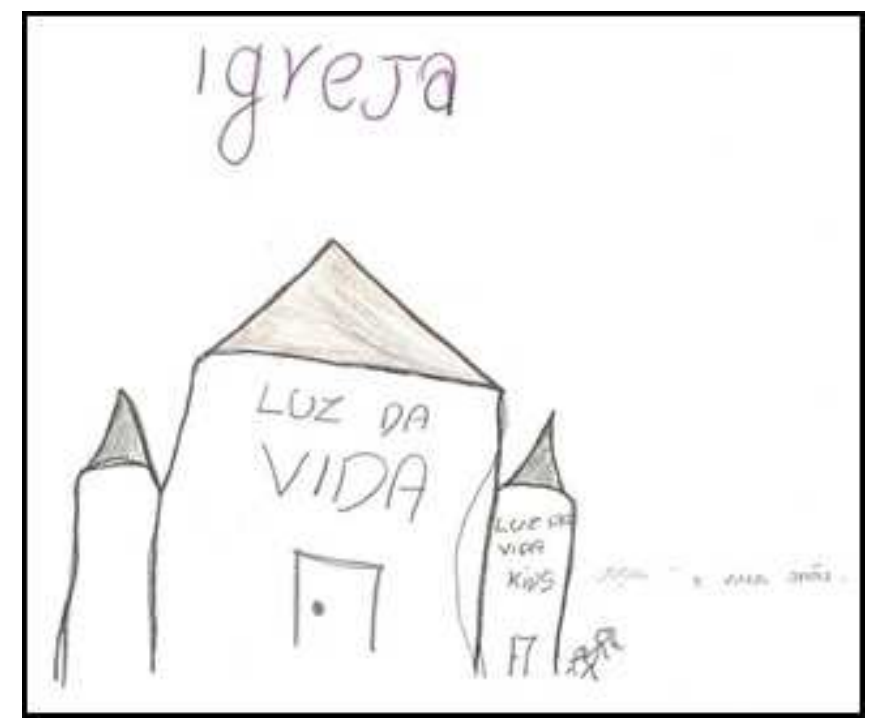

Figura 01: (Isabel, 8 anos)

$\mathrm{Na}$ figura 01 a temática "igreja" emerge com saliência na representação da criança acerca do tema religiosidade. Destaca-se neste desenho o nome da igreja e o espaço destinado exclusivamente para as crianças ("Kids"), conhecido também como "escolinha dominical". O culto infantil ou escola dominical teve origem em 1882 voltada para a dimensão de ensino bíblico adaptado ao público infantil. Inicialmente a proposta tinha como finalidade atender a demanda socioeconômica menos favorecida e após, acabou por incitar o desenvolvimento religioso de crianças, bem como a criação de rede de apoio social (Rodrigues, 2007).

Não obstante, dois outros participantes conceberam a igreja no âmbito mais concreto do lugar em si:

Igreja é onde a gente ora pra Deus... Tem um lustre enorme lá... As pessoas ficam orando. Tem aquele Deus lá, grudado na parede... As pessoas cantam também (Carla, 6 anos).

Igreja, é porque quando eles cantam uma canção (...). Na igreja, tem cadeira, tem teto (risos) (Alice, 6 anos).

Pode-se inferir que nas falas acima é característico o aspecto concreto, pautado num pensamento fixo à percepção dos eventos. Esta percepção relaciona-se de modo estreito a como a criança experimenta a partir da visualização, uma significação frente ao mundo externo (Belsky, 2010). Corroborando com tal análise, é visto que as crianças desta faixa etária por se encontrarem num estágio eminentemente concreto, só poderão se expressar se tiverem como base aquilo que percebem do mundo "real", utilizando sob esta perspectiva de perceber 0 mundo, os instrumentos operatórios e afetivos que possuem (Neves, 2005). 
Com fins ilustrativos, observa-se na figura 02, a ênfase conferida ao fator mais concreto em si quando ilustra o ambiente físico interior da igreja que frequenta destacando o display contendo o nome da igreja e o altar onde se realizam as pregações.

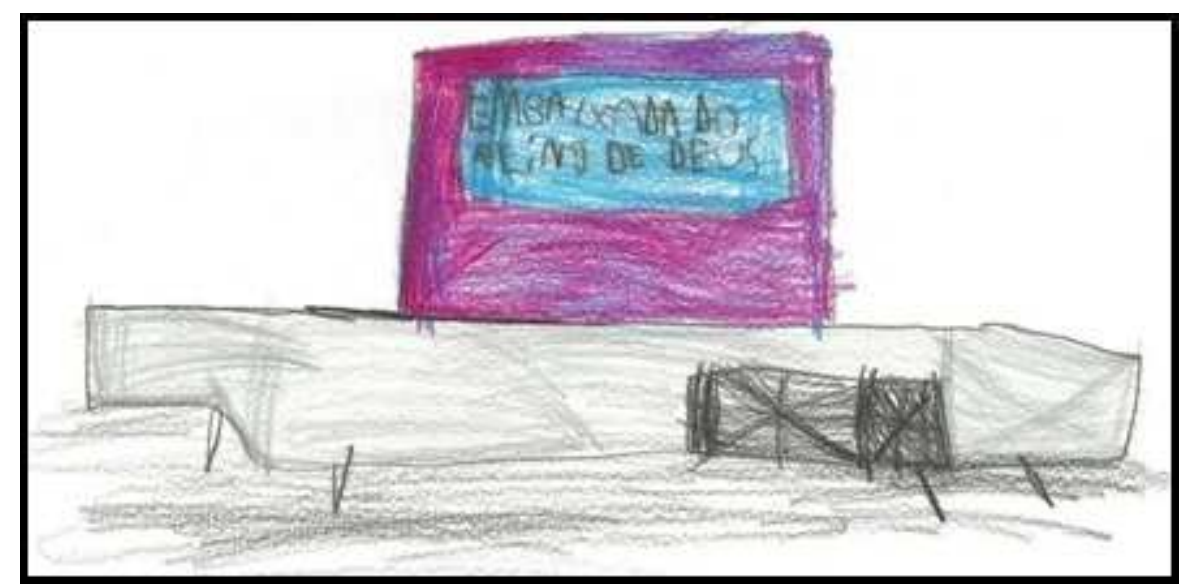

Figura 02: (Ricardo, 7 anos)

Ainda no que tange ao conceito de religiosidade, 09 de 10 crianças entrevistadas a relacionam à figura de Deus, Jesus e igreja a partir das experiências prévias que vivenciaram e aprenderam ante ao fenômeno pesquisado. $\mathrm{O}$ que se pode conferir nos relatos:

... eu lembro da escolinha da igreja. A gente pinta, desenha... A professora fala umas histórias sobre Deus. (Ricardo, 7 anos). O que eu penso sobre religião? Eu penso que foi Ele quem nos criou, né? A gente não pode fazer nada sozinho, Ele pode fazer tudo. A gente tem que fazer a nossa parte e Ele tem que fazer a parte Dele (Lucas, 9 anos).

Eu fico pensando em Jesus (Gabriela, 10 anos).

Observa-se de modo geral, que as crianças ao mencionarem sobre religiosidade, só conseguem defini-la a partir da existência de um Ser Transcendente. Sobre isto, encontraram-se resultados similares na pesquisa de Neves (2005) ao investigar sobre as primeiras indagações acerca da espiritualidade na percepção infantil. Desta feita, evidenciou-se para as crianças pesquisadas, que Deus é a figura central em qualquer religião e quando a temática sobre religiosidade e espiritualidade emergia os participantes só conseguiram responder relacionando-a com a figura divina.

No que se refere ao tipo de religião, nove de dez crianças pesquisadas manifestaram que aderem a algum tipo de religião. Predominou-se a religião cristã evangélica entre os sujeitos da pesquisa, seguidamente da religião cristã católica. Apenas um participante, de sete anos, não conseguiu definir o conceito de 
religião afirmando nunca ter ido a uma igreja, o que indica que a criança relaciona a aprendizagem dos conceitos religiosos a uma determinada instituição, a igreja.

Frente ao quesito das fontes de informações recebidas acerca da religiosidade, ambos os grupos de crianças descreveram o papel da família no ensino das práticas religiosas como leituras bíblicas e orações. Verificou-se também que a mídia e, neste caso, a televisão e os desenhos infantis; somado à figura do Padre, de diáconos e professores, constituíram-se como fontes significativas para o acesso de informações de cunho religioso para estas crianças. O que se pode constatar nos relatos demonstrativos:

O meu pai e a minha mãe me falam sobre religião. Eles dizem que é legal participar, que é pra agradecer a Deus por tudo aquilo que Ele tem feito... Aqui na escola também, a gente aprende sobre Deus, sobre as histórias da Bíblia, (...) todo dia antes de começar as aulas a gente tem que orar (Beatriz, 10 anos).

Minha vó, minha mãe e minha tia. Elas me falam sobre as coisas de Jesus. Tipo, quando Ele criou o mundo, quando criou as coisas (Mateus, 09 anos).

Nossa família se reúne com todo mundo, meus irmãos também... A gente ora junto e lê muito a Bíblia. Aqui na escola antes que a gente começa os estudos, a gente sempre ora. A gente também ora pelo nosso lanche, que abençoe todo mundo aqui da escola, os coordenadores, professores, tudo... Daí, quem quiser pede pra prof, orar (Lucas, 9 anos)

Interessante observar nas falas acima, a fonte recebida pelas crianças mediante os ensinamentos da escola. Nestes discursos, em especial, os participantes da "Escola A", evidenciaram vivências e envolvimento tanto por parte dos alunos quanto de toda instituição de ensino às práticas religiosas. Pode-se inferir que tal vivência aproxima estes participantes da dimensão religiosa-espiritual em seu cotidiano, não recebendo as informações somente dos familiares e das igrejas e/ou grupos religiosos que possam frequentar.

A partir da teoria do desenvolvimento religioso proposta por Amatuzzi (2001), cuja premissa se dá em etapas do desenvolvimento pessoal, toma-se como foco a formação e evolução de um conceito de eu que estabelece uma relação com o Transcendente, subdividindo-se em 9 etapas o desenvolvimento religioso. O estágio que contempla a faixa etária aproximada entre 7 a 12 anos compreende que a religiosidade para a criança é apropriada também através do sentido de narrativas e histórias que são contadas e reproduzidas entre as gerações. Tal perspectiva verificou-se nos discursos infantis, uma vez que se referem à ênfase dada aos ensinamentos bíblicos, mediante histórias 
que os pais, avós e professores contam. Considera-se que na dimensão religiosa, as orações, ritos e obediência a preceitos influenciam no desenvolvimento do sujeito quanto ao seu enraizamento religioso (grau de autenticidade ou vivência religiosa). Outro ponto fundamental de análise refere-se às práticas religiosas que os participantes evidenciaram em seus relatos. Estes informaram que uma pessoa para evidenciar a sua fé deve expressar determinadas práticas relacionadas a bons comportamentos $e$ aqueles que devem ser evitados:

Não brigar com os pais dela, nem com os irmãos... Não ter preconceito... (Gabriela, 10 anos).

Não falar palavrões, não fazer coisas ruins, não fazer coisas que magoem os outros e ir na igreja, claro (Isabel, 8 anos).

Tem que ter fé, orar... A minha irmãzinha que tem cinco anos, disse que tinha fé, ela foi pra casa e no outro dia, a perna dela tava melhor. Jesus curou ela (Ricardo, 7 anos).

Só receber Jesus. Tipo, a gente ora com as pessoas: "Querido Jesus, entra no meu coração, perdoa meus pecados, eu te recebo, amém" (Lucas, 9 anos).

Observam-se nos discursos acima diferentes características vinculadas às práticas religiosas. Os posicionamentos de Gabriela e Isabel parecem apontar uma perspectiva mais relacionada à moral geral que a religiosidade oportuniza, quando discorrem sobre comportamentos e hábitos que não devem ser praticados; enquanto que as narrativas de Ricardo e Lucas sugerem elucidar os aspectos mais relacionados à dimensão da religiosidade.

Sobre este quesito, Amatuzzi (2000) ressalta que o desenvolvimento religioso se processa simultaneamente ao desenvolvimento moral, cognitivo, social e afetivo, sendo que o desenvolvimento moral é um pré-requisito necessário, mas não suficiente para o estágio religioso. Sob a ótica piagetiana, a moralidade implica pensar no exercício de três dimensões: regras, princípios e valores. Assim sendo, as relações interindividuais que são regidas por regras contemplam, por sua vez, relações de coação - correspondente à noção de dever; e de cooperação - que pressupõe a noção de articulação de operações de dois ou mais sujeitos, envolvendo não apenas a noção de 'dever', mas a de 'querer' fazer (Terra, 2001).

Em contrapartida, os relatos de Ricardo e Lucas evidenciam mais aspectos concernentes às relações de cooperação e de um 'querer' fazer no âmbito das práticas religiosas. Sobre isto, os relatos presentes da experiência religiosa e espiritual parecem destacar-se quanto às dimensões do "dever", presentes no desenvolvimento moral. 
O desenho temático de Tiago (08 anos), figura 03, expressa de forma concisa às práticas religiosas como as orações e idas ao culto. Observa-se como temática central da projeção: a dinâmica do culto/ igreja onde freqüenta. Além das práticas, é interessante observar a altura do púlpito em relação aos fiéis e a atitude do pastor falando aos fiéis. Repara-se que o desenho possui detalhes, coloração e 0 tamanho das pessoas é proporcionalmente menor que o ambiente e a figura do pastor desenhada, dando destaque a este.

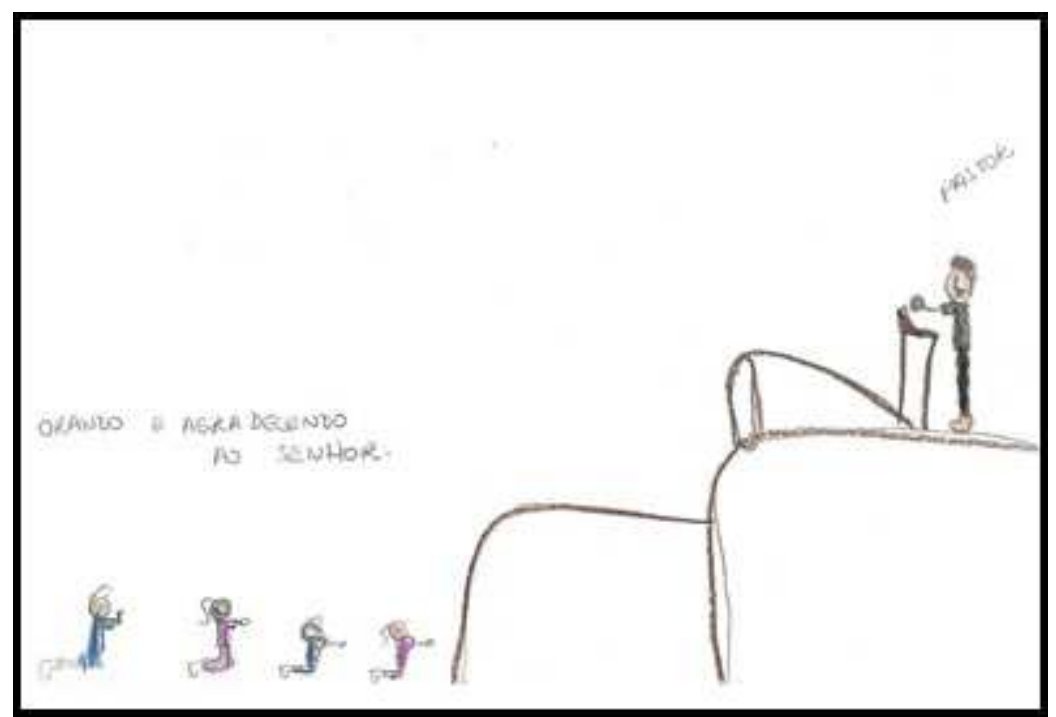

Figura 03: (Tiago, 8 anos)

Conforme Becker, Maestri e Bobato (2015), as práticas e recursos religiosos como as leituras bíblicas, oração, participação na igreja ou movimentos doutrinários, retiros e testemunhos de vida, quando vivenciados de modo sistemático e contínuo, mediados por pessoas significativas como autoridade religiosa (pastor, padre, líder religioso), pais e amigos, podem conduzir o sujeito a amadurecer e estabelecer sua identidade religiosa e espiritual.

Nota-se a relevância atribuída à dimensão da religiosidade, especialmente quando esta é vivenciada de forma cotidiana pelos participantes. Destaca-se o envolvimento parental dedicado às crianças no sentido de favorecer e significar o processo de desenvolvimento religioso destas. Tal reflexão pode ser observada nos discursos a seguir:

Eu oro, eu canto, eu danço pra Deus em casa. A gente também ora nas refeições (...) e combina assim: cada semana um ora. Tipo, uma semana meu pai ora, na outra minha mãe e depois, eu. A gente também faz pequeno grupo, eu participo com meus pais (Beatriz, 10 anos).

Lá em casa, a gente ora todo dia antes do almoço, quando a gente acorda, quando a gente vai dormir e quando acontece 
alguma coisa... A mãe lê a Bíblia comigo também (Tiago, 8 anos).

De acordo com Weber, Prado, Salvador e Brandenburg (2008), entende-se o envolvimento parental como a participação dos pais no desenvolvimento dos filhos, acerca de quanto estes os apóiam, são sensíveis às suas reações, estão presentes, disponíveis e demonstram afeto. Em relação a isto, os relatos acima expressam não somente 0 exercício das práticas religiosas, como concomitantemente proporcionam o fortalecimento dos vínculos familiares.

Dos 10 entrevistados, 09 afirmaram gostar de exercer as práticas religiosas e, quando inquiridos sobre por qual motivo, alegaram pelo fato de verem-se como membros participantes da sua comunidade.

Eu gosto de fazer novos amigos lá no culto das crianças e de fazer as tarefinhas lá, que eles pedem pra fazer (Isabel, 8 anos).

Para ouvir a voz do Senhor... Também gosto de ir no culto infantil e também vou no de adulto... Na escolinha, a gente aprende umas histórias, (...) Eu tô aprendendo ainda a Bíblia... Eu gosto de ler "Mateus (evangelho)", quando Jesus nasceu... (Tiago, 8 anos).

Eu gosto. Porque eu faço muitos amigos e também porque eu posso ter oportunidade de pregar pra eles também (...) Ás vezes a gente até vai nos lugares pra pregar para outras pessoas sobre Jesus, ... porque é a nossa missão, né? (Lucas, 9 anos).

Algumas crianças relacionaram a ida à igreja com o culto infantil, neste ínterim, percebe-se que os encontros religiosos destinados exclusivamente para elas parecem demonstrar um apreço significativo, uma vez que o lúdico parece propiciar aprendizagem no âmbito religioso e constituir-se ainda, como uma rede social para o desenvolvimento destes participantes.

Aponta-se também, no discurso de Lucas, o sentido existencial que perpassa tal doutrina indicando um nível de pensamento mais complexo acerca da formação religiosa para a vida das pessoas. Rodrigues (2007) argumenta que a vivência da religiosidade infantil, assim como a do adulto, oportuniza uma reflexão ao sentido de vida, com vistas à identificação da criança com as práticas religiosas, o que pode contribuir para a identidade religiosa e espiritual dos praticantes.

No que se reporta à finalidade da vivência religiosa para estas crianças, salientou-se a finalidade para o desenvolvimento da moralidade, bem como da aprendizagem da espiritualidade a partir 
da promoção do bem-estar experimentado por meio das práticas religiosas. Tal noção remonta as discussões que emergiram na categoria acerca das práticas religiosas, para tais crianças:

Para ficar um tempo com Deus, aprender mais sobre a vida Dele, de Jesus... Não fazer o mal (Gabriela, 10 anos).

Porque me faz bem, eu gosto bastante (Beatriz, 10 anos).

Porque eu quero ir para o céu, ser um ajudante de Jesus... Mas não só isso. Eu quero ajudar as pessoas a conhecer a verdade... A verdade é que Jesus nos criou. A gente não apareceu tipo do nada, ... Jesus tem um plano para cada um de nós (Lucas, 9 anos).

Outra característica observada nos relatos de algumas crianças refere-se ao pensamento típico do estágio operatório concreto uma vez que se percebe o dualismo entre o bem e o mal, oriundo do pensamento dualista. Tal análise vincula-se ao aspecto da classificação, mais uma vez encontrado no discurso de um participante que parece sinalizar indicativos do estágio operacional concreto:

É bom fazer orações, ter fé, porque se a gente não respeita Deus, a gente vai lá pra baixo quando morrer... Embaixo da igreja, eu tenho medo de dizer esse nome. Lá onde tem o carinha de vermelho com chifre... (Tiago, 8 anos).

O discurso de Tiago perpassa uma noção que transcende ao aspecto religioso, mas se pode evidenciar a preocupação em distinguir o bem e o mal, além de evidenciar os medos infantis comuns a crianças desta fase quanto a figuras monstruosas personificadas. São comuns no imaginário infantil figuras como de monstros, bruxas e outros personagens que simbolizem $0 \mathrm{mal}$, assim como aqueles que demonstram bondade e heroísmo, como as fadas, os anjos e os super-heróis. Tais representações caracterizam a dialética entre 0 bem e o mal; que ao mesmo tempo em que encantam, amedrontam as crianças (Pacheco,1995).

Na opinião de quase todas as crianças, é importante seguir uma religião e ir à igreja por aprenderem comportamentos assertivos, desenvolverem e aprimorarem as habilidades sociais, remontando 0 desenvolvimento da moral. O que se verifica nos relatos:

É importante pra saber as coisas que pode, que não pode... Que não pode falar mal uns dos outros, falar mal de outras pessoas, isso aí (Mateus, 9 anos).

É importante porque as pessoas vão ser melhores. Elas ficam bondosas... (Carla, 6 anos). 
É importante ir à igreja pelo o que Ele fez por nós... Ele foi crucificado na cruz. A gente precisa ter respeito e não falar mal. Precisa amar e aprender com Ele (Gabriela, 10 anos).

A partir dos discursos mencionados, verificaram-se duas ilustrações similares de crianças de diferentes escolas com a mesma faixa etária. Os desenhos estamparam o evento da crucificação, conforme se pode observar na figura 04 :

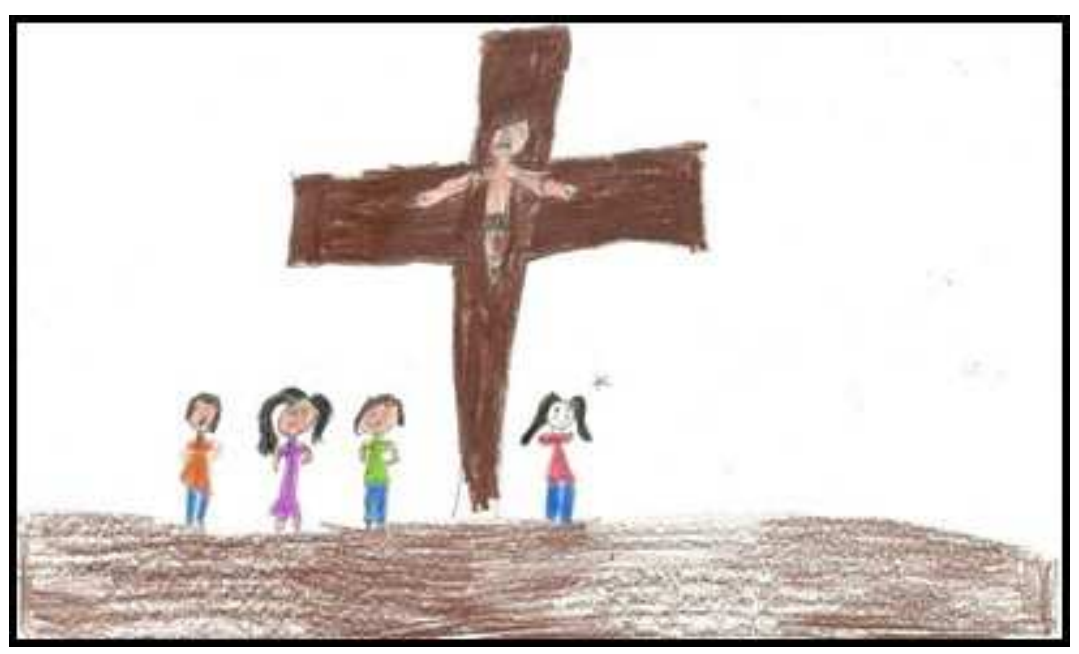

Figura 04: (Beatriz, 10 anos)

Para Beatriz, os demais personagens que acompanhavam a crucificação, tiveram diferentes sentimentos: "as pessoas más estavam felizes pela morte de Jesus e as pessoas boas estavam tristes e choravam pela morte Dele $(\ldots)^{\prime \prime}$. Novamente se percebe a relação entre o bem e o mal. Na percepção de Gabriela (10 anos) verificam-se outras noções acerca da crucificação de Cristo, passível de verificação a seguir na figura 05: 


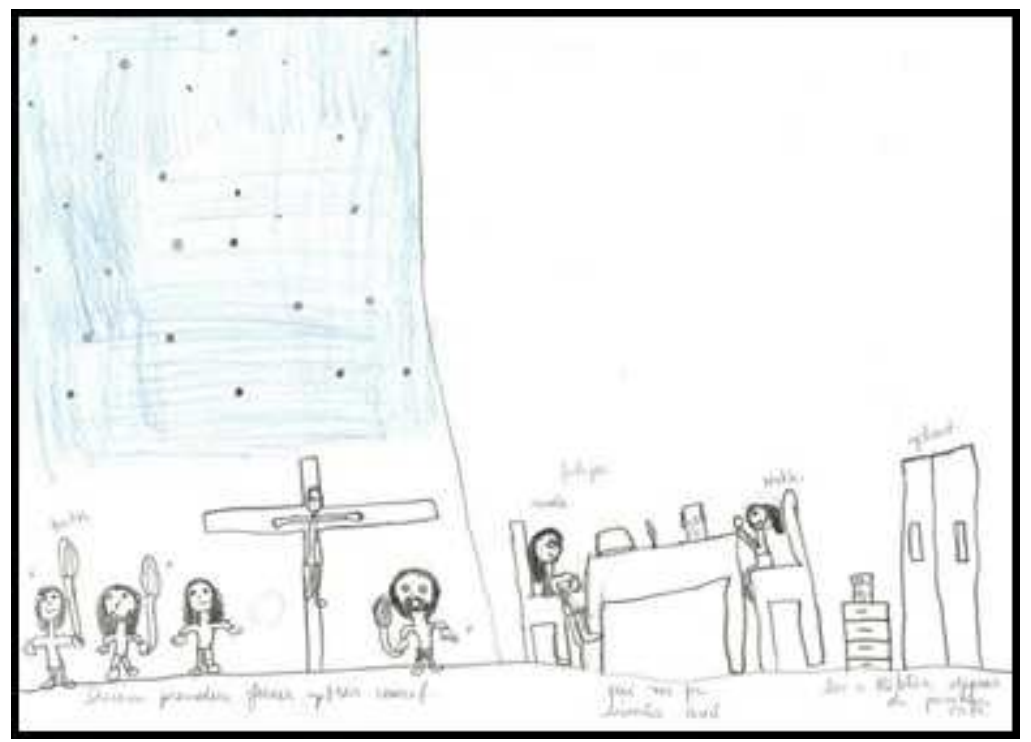

Figura 05: (Gabriela, 10 anos)

Esta apresentou no desenho dois eventos distintos: o primeiro relacionado à crucificação e o segundo, contempla a rotina da criança em sua família e a ênfase dada a Bíblia Sagrada na estante, que a participante explica ler após o jantar. Todavia, focando no primeiro evento projetivo, Gabriela enfatiza que os personagens ao redor da cruz significam os homens que prenderam Jesus para crucificá-lo.

Observam-se nos desenhos das duas crianças que a temática conferida se reporta à crucificação de Jesus Cristo e à relevância dada ao momento histórico, dotado de um simbolismo religioso e espiritual. Todavia, não foi passível de observação, noções de aprofundamento maiores a respeito da crucificação, como a finalidade para tal evento e como isto repercute e significa para tais crianças.

Outro conceito pesquisado fez menção ao que as crianças pensam sobre quem Deus é. Surgiram, pontos convergentes entre os relatos, como alusões à paternidade Divina:

Deus é o meu pai, é especial... Jesus é o meu coração... Porque Ele fez a gente (Carla, 6 anos)

Pra mim além de pai, Ele é meu amigão, eu amo Ele, adoro Ele (Ricardo, 7 anos).

Um pai... Uma coisa muito boa que sempre tá comigo. Sempre tá do meu lado, fazendo as coisas que eu faço, sempre tá me ajudando nas coisas... (Mateus, 9 anos).

Ele tá lá no céu e nos vê... Ele é um pai muito amoroso, veio muito pobre... Deus escolheu Jesus para ser Seu filho e cuida da gente (Gabriela, 10 anos). 
Consonante aos discursos acima, uma das crianças apontou no desenho temático a relevância dada ao céu como sendo o local que Deus habita e ainda, poder cuidar e estar presente na vida humana:

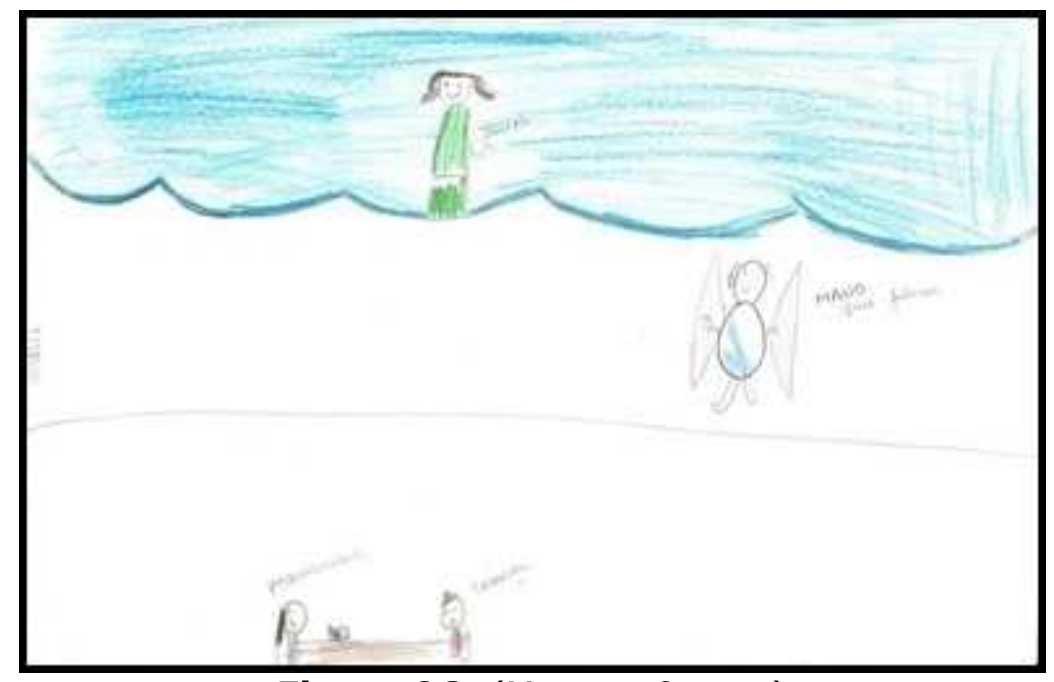

Figura 06: (Mateus, 9 anos)

De acordo com o relato da criança, o desenho acima ilustra a figura de Deus como Jesus que tem a função de cuidar, observar e proteger as pessoas. Interessante perceber nesta ilustração que Mateus dividiu alguns aspectos do ambiente, como a noção de espaços distintos: Jesus no céu e o anjo em espaço mediador entre o céu e a terra. Sobre isto, alegou que a gente "não vê a Deus, os anjos (...) são transparentes, mas eles existem". Nesta perspectiva, vislumbra-se uma transitoriedade entre o estágio cognitivo operatório concreto para o operatório formal, pois ainda residem aspectos concretos quanto à personificação Divina. No entanto, já se pode pensar na abstração recorrente quando menciona a presença e a proteção de Deus, mesmo este sendo transparente. Além disto, observa-se o aspecto temporal que a criança relacionou, ao estampar ela própria e a pesquisadora, em uma dimensão do "aqui e o agora", enquanto as demais esferas espirituais trabalham juntas ao meio terreno.

A análise acima ratifica os resultados obtidos nos estudos de Neves (2005) quanto às percepções infantis sobre o Sagrado. Na pesquisa referida, verificou-se que algumas crianças relacionaram a figura divina como "transparente" com projeções aladas, dotada de poderes sobrenaturais como a onisciência e a onipresença.

Compreenderam-se ainda nos relatos, atribuições a Deus como o Criador da vida humana e presença constante, personificando-O, como segue os discursos:

Foi Ele que nos criou. Ele fez a gente (...) Eu imagino Ele lá do céu, revestido de branco no trono, com seu filho do lado Dele, 
Jesus e o Espírito Santo do lado Dele também, com uma coroa, com barba... (Lucas, 9 anos).

É um cara de roupa branca, legal, divertido e bonito, como Jesus, que é quase a mesma coisa. Eu sempre agradeço por Ele ter criado o mundo (Tiago, 8 anos).

Como exemplo destas características, a ilustração da figura 07 expressa tal fenômeno:

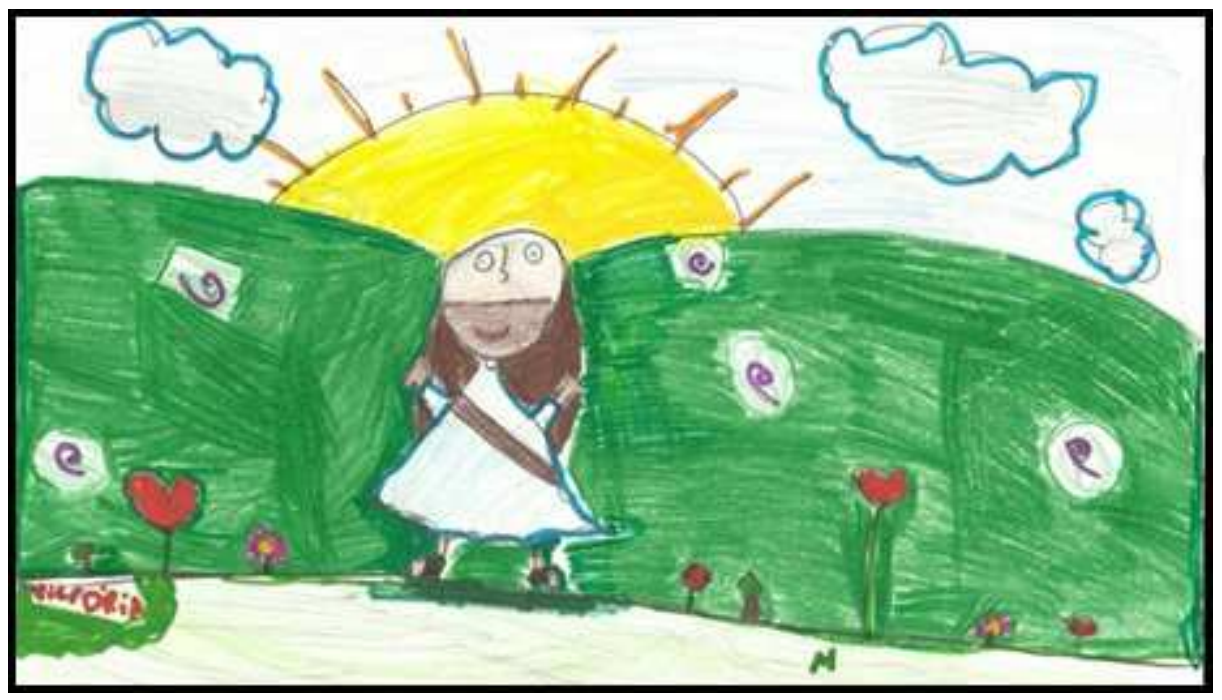

Figura 07: (Carla, 6 anos)

Evidencia-se a partir do desenho, as noções atribuídas a figura de Deus como de um homem com cabelos longos, de barba e vestindo uma túnica. Nota-se na projeção uma riqueza de detalhes de elementos e a coloração bem distinta e marcante entre os objetos desenhados.

Em vista deste cenário, uma das ideias sobre Deus e das práticas religiosas que permeiam o imaginário infantil é o antropomorfismo, ou seja, a projeção de características humanas na figura Divina. Pode-se pensar que a concepção de Deus como um homem seja a imagem mais forte que as crianças concebem, parecendo ser uma tendência natural do desenvolvimento infantil. Tal aspecto se explica através do predomínio nesta fase do desenvolvimento cognitivo do pensamento concreto, que interpreta o mundo de forma literal. Neste sentido, associar a imagem de Deus à figura humana seria uma maneira mais clara e de fácil entendimento para as crianças (Neves, 2005).

Apenas um participante não conseguiu definir de modo preciso a representação de Deus, que por sua vez atribuiu às "pessoas deuses" que assistiu num programa infantil de televisão da qual recebeu algumas informações sobre deuses e anjos, respectivas do apresentador. No desenho temático, o participante não atende a 
finalidade da consigna, uma vez que desconhecia o assunto em questão, no entanto, pautou-se a partir da referência que detinha sobre o tema. Tal referência é postulada a partir da fonte midiática conforme se verifica na figura 08 :

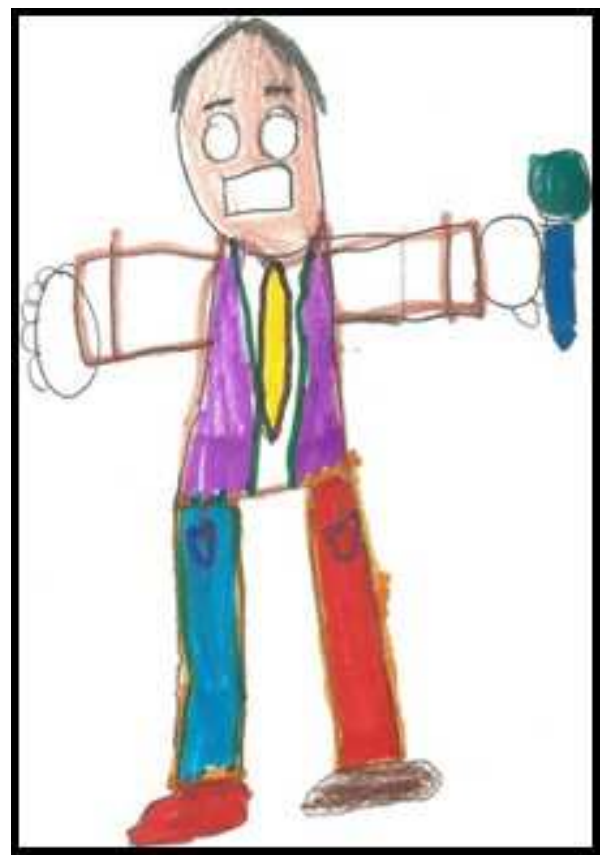

Figura 08: (Samuel, 7 anos)

É válido discorrer que o participante ora citado demonstrou significativo desconhecimento em relação à temática pesquisada, pois relatou que em sua família a vivência da religiosidade não é experimentada, e, portanto, nunca foi a uma igreja, sabendo tampouco descrever sobre o que seria religião e as práticas religiosas:

Não tenho idéia... Na minha casa não tem nada sobre Deus, sobre Jesus (Samuel, 07 anos).

O discurso acima é passível de observação quanto às características pelas quais o sistema familiar de Samuel é constituído. Pode-se inferir que os valores religiosos que perpassam as doutrinas e os ensinamentos relacionados à crença em um Ser superior parecem não fazer parte do contexto familiar e escolar aos quais a criança pertence. Deste modo, Amatuzzi (2001) sinaliza que se não houver estímulos ou significações religiosas contundentes para a família ou grupo social que permeia o contexto de vida da criança, o desenvolvimento religioso será acometido possivelmente de uma ruptura posterior, pela falta de experiência quanto ao assunto. No entanto, verifica-se no relato de Samuel que este se refere a Deus e Jesus como sendo do domínio religioso. 
Conforme Hartwig (2014) é importante que o sistema educacional não perca de vista os alunos que não são adeptos de nenhuma religião, tendo em vista a inclusão social que perpassa diferentes âmbitos, designados pela classe social, idade, sexualidade, etnia e crenças religiosas. Deste modo, promover o ecumenismo religioso capaz de contemplar diferentes formas de expressão religiosa/espiritual, e ainda, à ausência destas, se propõe um modelo ético e humanizado de acolher o público vigente.

\section{Considerações Finais}

A experiência da religiosidade e das indagações a procura do sobrenatural desde a tenra infância constituem um curioso cenário de como a pessoa fundamenta suas ideias a respeito de temas abstratos. Deste modo, foi objetivo da presente pesquisa analisar as concepções acerca da religiosidade que crianças escolarizadas entre 6 a 10 anos de idade possuem.

Em vista disto, a análise de dados evidenciou determinadas divergências de resultados no que se refere ao tipo de escola investigada, bem como do estágio cognitivo em que as crianças se encontram. Neste sentido, verificou-se que os participantes da Escola A manifestaram receber mais informações de cunho religioso e serem incentivados às práticas religiosas a partir do papel dos professores da própria escola, indicando que os princípios religiosos fazem parte do seu projeto pedagógico. $O$ que foi verificado com menor intensidade no discurso dos participantes da Escola B.

Sobre o quesito das práticas religiosas, verifica-se a função estabelecida pela família, quando esta oportuniza maior vivência da religiosidade nas atividades cotidianas da criança. Tal apontamento foi mais verificado pelos participantes da Escola A. Quanto a isto, destaca-se o envolvimento parental como significativo marco no desenvolvimento infantil desses participantes.

Outro fator divergente reporta-se à finalidade das práticas religiosas. Para as crianças da Escola B, remonta novamente a perspectiva de tornar-se "uma pessoa melhor" e não praticar determinados comportamentos considerados negativos. Ou seja, vislumbra-se a religiosidade como um norteador para desenvolverem e aprimoraram as habilidades sociais. Enquanto que para as crianças da Escola A de modo geral, a importância em aderir determinada religião se pauta sobre um viés que permita ao sujeito desenvolver a espiritualidade pelo bem-estar experimentado.

Não obstante, quanto às concepções que as crianças possuem acerca de Deus, não se verificaram dados substancialmente distintos, mas similares, uma vez que a representação que a maioria nutre em 
relação ao símbolo Divino é perpassada por uma noção concreta e personificada a partir do estágio cognitivo em que se encontram.

Tomando como pressuposto teórico o desenvolvimento cognitivo piagetiano, verificaram-se características distintas entre os participantes, especialmente nas faixas etárias entre 6 a 8 anos e de 9 a 10 anos de idade. A partir dos discursos e das temáticas projetivas do estudo, observou-se que as crianças entre seis a oito anos, independentemente da escola que frequentam refletiram de modo geral um pensamento mais concreto fixado à percepção dos eventos religiosos concernentes aos aspectos físicos do ambiente onde se expressa a religiosidade, neste caso, das igrejas; além de demonstrarem certo egocentrismo, característico da faixa de desenvolvimento cognitivo-emocional, uma vez que relacionaram em alguns discursos a vivência da religiosidade a partir das próprias experiências e das práticas religiosas cotidianas. Ainda foi possível identificar que fatores como a classificação entre a dicotomia do bem e do mal; dos tipos de credo e do pensamento dualista, foram observados com recorrência, especialmente entre crianças de sete a oito anos.

Observaram-se ainda, características peculiares ao estágio préoperatório, cujo entendimento pressupõe uma inteligência simbólica a partir do egocentrismo, uma vez que a criança não concebe uma realidade da qual não faça parte, devido à ausência de esquemas conceituais e da lógica; além de conceber a religiosidade mediante os próprios sentidos restritos às percepções imediatas, dando-lhe, portanto, uma noção fluida e mágica.

Não obstante, a faixa etária acima contemplou indicativos do estágio operatório-concreto, sendo estes os aspectos mais significativos observados no tipo de cognição, evidenciado pela crescente capacidade de raciocinar sobre o mundo de modo mais lógico e adulto, distinguindo-se com maior facilidade a fantasia da realidade, sendo capaz de classificar objetos e seriá-los.

Já para as crianças de nove a dez anos, demonstraram-se tanto aspectos mais concretos de compreender os fenômenos religiosos quanto pareceram esboçar um ensaio para um pensamento mais abstrato, dotado de simbolismos, não enxergando apenas a finalidade da vivência religiosa para si próprias, mas como uma contribuição para a vida das demais pessoas e para o bem comum. Sob este panorama, deflagra-se, portanto, características oriundas do estágio operatório formal, as quais abarcam a abstração e o raciocínio sobre hipóteses. Neste ínterim, reiterou-se o ensaio não apenas para as determinações que a religião imputa; dando assim, respaldo para o desenvolvimento da espiritualidade, haja vista a discussão dos relatos em torno da "missão de vida" e no bem-estar experimentado a partir das práticas religiosas, o que se pode pensar numa perspectiva com vistas ao exercício da espiritualidade. 
A partir deste estudo, cumpre registrar que pesquisas acerca da religiosidade e da espiritualidade na perspectiva infantil são por ora escassas na literatura. Em vista disto, sugere-se que os recentes estudos relacionados ao desenvolvimento religioso-espiritual visem também enfocar os aspectos condizentes ao contexto no qual a criança está inserida, incluindo ainda, manifestações ecumênicas de expressão da religiosidade e espiritualidade em diferentes espaços ao considerar as diversas significações acerca do Transcendente em cada etapa do desenvolvimento humano.

\section{Referências}

Almeira, A. M., Pinsky, L., Zaleski, M., \& Laranjeira, R. (2010). Envolvimento religioso e fatores sociodemográficos: resultados de um levantamento nacional no Brasil. Rev. Psiq. Clín., 37, 1, 12-15.

Amatuzzi, M. (2000). O desenvolvimento religioso: uma hipótese psicológica. Estudos de Psicologia, 17 (1), 15-30.

Amatuzzi, M. (2001). Teoria do desenvolvimento religioso: Um trabalho de psicologia e religião? In. Paiva, G. J. (Org.)., Entre necessidade e desejo: Diálogos da Psicologia com a Religião, (pp. 64-66). São Paulo: Edições Loyola.

Becker, A. P. S., Maestri, T. P., \& Bobato, S. T. (2015). Impacto da religiosidade na relação entre pais e filhos adolescentes. Arquivos Brasileiros de Psicologia, 67 (1), 84-98.

Bellodi, P. L., Romão J. J. E., \& Jacquemin, A. (1997). Crianças em diálise: estudos das características de personalidade através de técnicas projetivas. J. Bras.Nefrol, 19 (2), 132-137.

Belsky, J. (2010). Desenvolvimento humano: Experienciando o ciclo da vida. Porto Alegre: Artmed.

Campos, L. F. de L. (2004). Métodos e técnicas de pesquisa em psicologia. São Paulo, Campinas, $5^{a}$ Ed.: Alínea.

Cardoso, M. C. S., \& Ferreira, M. C. (2009). Envolvimento Religioso e Bem-Estar Subjetivo em Idosos. Psicologia Ciência e Profissão, 29 (2), 380-393.

Franco, M. L. P. B. (2005). Análise do Conteúdo. Brasília, 2a ed.: Liber Livro Editora.

Gobatto, C. A., \& Araujo, T. C. C. F. (2013). Religiosidade e espiritualidade em oncologia: Concepções de profissionais da saúde. Psicologia USP, 24 (1), 11-34.

Goldberg, L. G., Yunes, M. A. M., \& Freitas, J. V. (2005). O desenho infantil na ótica da ecologia do desenvolvimento humano. Psicologia em estudo, 10 (1), 97-106. 
Hartwig, F. B. (2014). A escola laica de jovens e adultos, a partir de uma perspectiva democrática-autônoma. Trabalho de conclusão do II Curso de Especialização em Educação na Diversidade e Cidadania, Universidade de Brasília - UnB, 48p.

Minayo, M. C. de S. (1998). Pesquisa Social: teoria, método e criatividade. Petrópolis: Vozes.

Mota, S. G. (2005). As fronteiras da fé na criança: Descobrindo as relações sócio-religiosas da espiritualidade infantil. Monografia de graduação em Teologia não-publicada. Curso de Teologia, Universidade Metodista de São Paulo, 87p.

Neves, J. L. (1996). Pesquisa qualitativa - características, usos e possibilidades. Cadernos de pesquisas em Administração, 1 (3), 1-5.

Neves, M. A. C. M. (2005). Primeiras indagações e a procura do sobrenatural. Rev. Magis. Cadernos de Fé e Cultura, (47), 4053.

Pacheco, E. D. (1995). A linguagem televisiva e o imaginário infantil. Comunicação e educação, (2), 43-48.

Paiva, G. J. (2011). Psicologia e Espiritualidade. Anais do IV Congresso de Psicologia - UNIFIL. Londrina, PR, Brasil, 1-7.

Piaget, J. Seis estudos de psicologia. Rio de Janeiro, 24ed.: Forense Universitária, 1999.

Pietrukowicz, M. C. L. C. (2001). Apoio social e religião: uma forma de enfrentamento dos problemas de saúde. Dissertação de mestrado em Saúde Pública não-publicada, Escola Nacional de Saúde Pública, Fundação Oswaldo Cruz, Rio de Janeiro, RJ, $117 p$.

Rodrigues, M. W. (2007). Formação continuada de educadores cristãos - Vivendo a fé cristã no culto infantil. Dissertação de mestrado em Teologia não-publicada, Escola Superior de Teologia, Instituto Ecumênico de Pós-Graduação, São Leopoldo, RS, $115 p$.

Terra, M. R. (2001). O desenvolvimento humano na teoria de Piaget. Recuperado em 15 outubro, 2014, de http://www.unicamp.br/iel/site/alunos/publicacoes/textos/d000 05.htm

Weber, L. N. D., Prado, P. M., Salvador, A. P. V., \& Brandenburg, O. J. (2008). Construção e confiabilidade das escalas de qualidade na interação familiar. Psicologia Argumento, 26 (52), 55-65.

\section{Endereço para correspondência}

Ana Paula Sesti Becker

Universidade Federal de Santa Catarina, Laboratório da Saúde, Família e Comunidade (LABSFAC)

Avenida César Seara, Carvoeira, CEP 88040500, Florianópolis - SC, Brasil

Endereço eletrônico: anapaulabecker.psicologia@gmail.com 


\section{Josiane Delvan da Silva}

Universidade do Vale do Itajaí, Centro de Educação Superior de Ciências da Saúde, Curso de Psicologia

Rua Uruguai, 458 - bloco 25 B, Centro, CEP 88302-202, Itajai - SC, Brasil

Endereço eletrônico: josidelvan@univali.br

Recebido em: 23/06/2016

Reformulado em: 23/07/2017

Aprovado em: 28/07/2017

\section{Notas}

* Doutoranda em Psicologia pela Universidade Federal de Santa Catarina PPGP/UFSC, vinculada ao Laboratório de Psicologia da Saúde, Família e Comunidade (LABSFAC/UFSC) Linha de pesquisa: Saúde, Família e Desenvolvimento Psicológico. Possui graduação em Psicologia pela Universidade do Vale do Itajaí, UNIVALI (2012) e Mestrado em Psicologia pela Universidade Federal de Santa Catarina (2014) na área de concentração: Saúde e Desenvolvimento Psicológico. É especialista em Psicologia Clínica com formação em Terapia Familiar Sistêmica pelo Instituto Familiare (2017). Atualmente é pesquisadora bolsista/CAPES, integrante do grupo de pesquisa do Laboratório - LABSFAC e tutora psicopedagógica vinculada ao PIAPE/UFSC - Programa Institucional de Apoio Pedagógico aos Estudantes da UFSC. Interessa-se principalmente pelos seguintes temas: apego, conjugalidade, envolvimento parental, desenvolvimento infantil e afetividade.

** Possui graduação em Psicologia pela Universidade do Vale do Itajaí (1992), graduação em Pedagogia pela Universidade do Vale do Itajaí (1990), mestrado em Psicologia pela Pontifícia Universidade Católica do Rio Grande do Sul (2000) e doutorado em Psicologia pela Universidade de São Paulo (2007). Atualmente é coordenadora do curso de Psicologia da Universidade do Vale do Itajaí e professora na disciplina de Psicologia do Desenvolvimento Humano, Orientadora de Estágio Curricular Obrigatório e de Trabalho de Iniciação Científica. Tem experiência na área de Psicologia em Desenvolvimento de crianças, atuando principalmente nos seguintes temas: crianças, parentalidade e saúde mental na infância. 